\title{
Chinese Learners’ Attitudes Toward Instructional Strategies
}

\author{
YANG Shu-yi \\ University of Iowa, Iowa City, USA
}

\begin{abstract}
This study investigated learners' emotional response towards nine instructional strategies commonly applied in Chinese classrooms within the theoretical framework of Affective Filter Hypothesis. The theory posits that individuals whose attitude more conducive to instructional strategies will have a lower filter and let more input in. A semi-structured survey design was adopted in this study of 72 Chinese learners. Results showed that learners with more negative attitudes toward the instructional strategies also expressed that they had difficulty in the classroom, indicating that their strong filter prevented them from seeking and taking more input. Results also demonstrated individual differences in responses. In general, participants were satisfied with strategy of adjusting tasks based on learners' need, organizing pair and group work, using adequate amount of target language, applying multimedia technology, and providing drills. While for some learners, certain instructional strategies made their classroom experience an anxious one such as strategy of providing opportunities for learners to give presentations, requiring the use of personal information and sensitive topics in language tasks, and giving in-class quiz. Pedagogical recommendations were made that instructors should be sensitive and flexible when designing tasks and pay attention to how learners respond so that successful instruction can be realized for as many learners as possible.
\end{abstract}

Keywords: Chinese as second language learners, attitudes, instructional strategies

\section{Introduction}

It has been widely accepted that many factors play roles in second language acquisition. There has been a large amount of research with the focus on cognitive factors while affective factors have been so far underexplored. The lack of attention to affective factors has been also shown in the studies of instructional strategy evaluation, which mainly talked about the instructors' and learners' views on the effectiveness and interesting degree.

This paper will first review Krashen's (1981) Affective Filter Hypothesis and summarize studies concerning the evaluation of instructional strategies. In the following sections, the findings of a study on Chinese learners' attitudes toward various instructional strategies will be reported and pedagogical recommendations based on the results will be given.

\section{Background}

\section{Affective Filter Hypothesis}

Krashen (1981) was among the first scholars who paid attention to the affective factors in L2 acquisition.

YANG Shu-yi, teaching assistant, Ph.D. student, Asian \& Slavic Languages and Literatures, University of Iowa. 
His Affective Filter Hypothesis proposes that individuals whose attitude more conducive to instructional strategies will have a lower filter and let more input in, which leads to better acquisition. On the contrary, when learners are troubled by some negative feelings such as anxiety and anger, they will have a higher filter which resists the L2 input from being received and turned into intake.

Many researchers have examined the effect of anxiety on L2 acquisition. Their findings suggested that anxiety generally plays a detrimental role in language learning (Horwitz, Horwitz, \& Cope, 1986; Horwitz, 2001; Bailey, Onwuegbuzie, \& Daley, 2000; Gregerson, 2003; Liu \& Jackson, 2008; ZHANG, 2001) while in some cases, moderate anxiety might enhance the acquisition of L2 (Scovel, 2006) as it triggers higher motivation.

\section{Evaluation of Instructional Strategies}

Instructional strategies refer to those adopted by the instructors in classroom with the purpose of assisting learners in their L2 acquisition. Studies concerning instructional strategy evaluation fall into two categories.

The first category concerns the effectiveness of instructional strategies. Y. WANG (2004) investigated English teachers' and learners' opinions on 16 instructional strategies including class discussion, multimedia application, and group work. Results demonstrated a striking difference between teachers and learners. Teachers preferred the use of class discussion, motivated by the theories of communicative teaching method. However, learners tended to opt for more traditional, focus-on-form classroom activities such as drills and they attached more value to instructional strategies which incorporated multimedia technology. In her series of studies on the effectiveness evaluation of instructional strategies in Chinese as second language classrooms, DING (2006a, 2006b, 2007) detected differences both between the instructors and learners, and between learners from different L1 backgrounds. The instructors emphasized the combination of traditional focus-on-form and newly developed communicative activities while only gave limited recognition to the effectiveness of online teaching. European and American learners paid more attention to the training of reading and writing and preferred individual activities to group work. Japanese-speaking learners, on the other hand, sequenced free activity as the best strategy, followed by the controlled activity. The activities focusing on the input alone were considered the least effective. Meanwhile, Japanese students were more likely to receive the guidance from the instructor and more willing to take oral production exercise as well as learn the grammatical rules.

Another category mainly discusses the interesting degree of instructional strategies. For example, WU and LIU (2009) analyzed the views of different cognitive style learners on their favorite instructional strategies. Results showed that in general learners regarded language game, pair work, and group discussion as the most interesting instructional strategies. Field-dependent learners favored debate more than field-independent learners. Having compared teachers' and learners' favorite instructional strategies, NI (2007) argued that learners considered the pair or group communication as interesting while the instructors believed role play and language game were greeted by learners.

The first researchers who focused on learners' emotional attitudes toward instructional strategies were Nicolson and Adams (2010). They examined five strategies including the use of personal information in tasks, pair and group work, target language as classroom language, physical movement, and student opportunity to 
opt out of or adapt tasks among ESL learners. An attitude scale containing adjectives of happy, willing, comfortable, dismayed, anxious, and angry was constructed to yield learners' emotional responses. The patterns of three groups of learners have emerged. The first group was labeled as active participant who always held positive attitudes toward instructional strategies. The second group was anxious learner, with more negative feelings in classroom. The third group contained necessary evil viewers who could attend the classroom activities from a more practical perspective although they resisted these activities emotionally.

Based on the previous literature, nine instructional strategies were classified for the present study. They are: the use of personal information and sensitive topics in tasks, target language as classroom language, pair and group work, physical response activity, task adjustment based on learners' need, opportunity to give presentations, drill, in-class quiz, and multimedia technology application.

The study attempts to explore the following research questions: (1) What attitudes do Chinese as second language learners hold toward the nine instructional strategies? (2) How are the nine instructional strategies used in Chinese as second language classroom?

\section{Method}

\section{Participants}

Seventy-two Chinese as second language learners from Beijing Language and Culture University participated in this study (30 males and 42 females, average age: 23). They are from about 20 countries such as South Korea, Indonesia, German, and US.

\section{Instrument}

A questionnaire of Chinese as second language learners' attitude toward instructional strategy was constructed for this study. There were three main sections for each of the nine instructional strategies. The first section was designed to investigate the frequency of the use of a specific strategy in Chinese classroom. Participants were asked to choose from a range of options such as never, occasionally, and always to reflect the condition of their classrooms. The second section mainly discussed learners' attitudes toward each instructional strategy. Three categories of responses were established. The comfort category included positive reactions displayed by adjectives like comfortable, confident, and satisfied. On the contrary, the anxiety category contained rather negative adjectives like unsatisfied, reluctant, embarrassed, anxious, and angry. The last category covers other emotional responses. The third section required participants to give short descriptions about the reasons of their attitudes. The examples were listed in Table 1.

Table 1

Examples of Each Section in the Questionnaire

\begin{tabular}{|c|c|c|}
\hline & Stimulus & Responses \\
\hline Section 1 & How often is the strategy used in your classroom? & Never, Seldom, Occasionally, Sometimes, Mostly, Always \\
\hline \multirow{3}{*}{ Section 2} & \multirow{3}{*}{ What do you feel about the strategy? } & Comfort: Willing, Comfortable, Confident, Satisfied \\
\hline & & $\begin{array}{l}\text { Anxiety: Unwilling, Unsatisfied, Reluctant, Embarrassed, } \\
\text { Dismayed, Anxious, Angry }\end{array}$ \\
\hline & & Other: Other \\
\hline Section 3 & Why do you feel that way? & \\
\hline
\end{tabular}




\section{Results}

\section{Overall Attitudes Toward Instructional Strategies}

According to Table 2, personal information and sensitive topics were not frequently used in Chinese classrooms.

Table 2

The Frequency of Personal Information and Sensitive Topics

\begin{tabular}{lllllll}
\hline & Never & Seldom & Occasionally & Sometimes & Mostly & Always \\
\hline Total & 13 & 20 & 16 & 14 & 8 & 1 \\
$\%$ & $18.1 \%$ & $27.8 \%$ & $22.2 \%$ & $19.4 \%$ & $11.1 \%$ & $1.4 \%$ \\
\hline
\end{tabular}

Table 3

Learners' Attitudes Toward Personal Information and Sensitive Topics

\begin{tabular}{lllllllc}
\hline & Willing & Confident & Unwilling & Reluctant & Embarrassed & Anxious & Other \\
\hline Total & 23 & 2 & 11 & 8 & 10 & 6 & 9 \\
$\%$ & $31.9 \%$ & $2.8 \%$ & $15.3 \%$ & $11.1 \%$ & $13.9 \%$ & $8.33 \%$ & $12.5 \%$ \\
\hline
\end{tabular}

As seen in Table 3, about 30\% of the participants felt comfortable with the presence of personal information and sensitive topics in the instruction. The majority of them were from Western countries. Sharing personal information and discussing sensitive topics were common in their educational tradition.

It is ok for me to tell others about my family or hobby, or share my views about some sensitive issues. We often do that back in US. [United States]

Almost half of the participants, however, held negative reaction toward this instructional strategy. They were mainly from Asian countries, valuing privacy and often worrying about their personal images.

I think this is personal privacy. I'd rather not share it with others. [Indonesia]

I don't want to talk about sensitive issues because others would judge you and you might have some wrong ideas. [Japan]

Table 4

The Frequency of Target Language as Classroom Language

\begin{tabular}{lllll}
\hline & Solely & Mainly & Partially & Rarely \\
\hline Total & 30 & 33 & 8 & 1 \\
$\%$ & $41.7 \%$ & $45.8 \%$ & $11.1 \%$ & $1.4 \%$ \\
\hline
\end{tabular}

It could be seen in Table 4 that the target language was the dominant language in Chinese classrooms.

Table 5

Learners' Attitudes Toward Target Language as Classroom Language

\begin{tabular}{llllll}
\hline & Satisfied & Unsatisfied & Anxious & Angry & Other \\
\hline Total & 58 & 2 & 5 & 1 & 5 \\
$\%$ & $80.6 \%$ & $2.8 \%$ & $6.9 \%$ & $1.4 \%$ & $6.9 \%$ \\
\hline
\end{tabular}

Table 5 showed that the vast majority of participants were satisfied with the use of target language in classroom. They claimed that the extensive use of L2 provided adequate amount of input, which was essential 
for L2 acquisition. Some of them also mentioned that the instructors' use of L2 would facilitate their comprehension.

I like it if the instructor speaks a lot of Chinese. Because I'm here to learn Chinese. I need to listen to it as more as possible. [Germany]

It is helpful for my listening comprehension. [South Korea]

Table 6

The Frequency of Pair and Group Work

\begin{tabular}{llllllc}
\hline & Never & Seldom & Occasionally & Sometimes & Mostly & Always \\
\hline Total & 0 & 4 & 11 & 36 & 12 & 9 \\
$\%$ & $0 \%$ & $5.6 \%$ & $15.3 \%$ & $50 \%$ & $16.7 \%$ & $12.5 \%$ \\
\hline
\end{tabular}

As indicated in Table 6, pair and group work was moderately used in Chinese classrooms. There were some classrooms with a lot of pair and group activities (about 30\%) and in other classrooms this instructional strategy was not quite often adopted (about 20\%).

Table 7

Learners' Attitudes Toward Pair and Group Work

\begin{tabular}{llllll}
\hline & Willing & Confident & Unwilling & Anxious & Other \\
\hline Total & 58 & 1 & 3 & 5 & 5 \\
$\%$ & $80.6 \%$ & $1.4 \%$ & $4.2 \%$ & $6.9 \%$ & $6.9 \%$ \\
\hline
\end{tabular}

According to Table 7, it seemed that most participants were willing to take part in pair and group activities. They believed that pair and group work offered more opportunities to communicate and negotiate meaning in L2. They also enjoyed the cooperative atmosphere among pair and group members.

I can talk more when I work with others. [Netherland]

We often need to say more to complete the task, which is beneficial for Chinese learning. [Russia]

I like the cooperation between members. We help each other. [United States]

Table 8

The Frequency of Physical Response Activities

\begin{tabular}{lllllll}
\hline & Never & Seldom & Occasionally & Sometimes & Mostly & Always \\
\hline Total & 7 & 13 & 21 & 24 & 6 & 1 \\
$\%$ & $9.7 \%$ & $18.1 \%$ & $29.2 \%$ & $33.3 \%$ & $8.3 \%$ & $1.4 \%$ \\
\hline
\end{tabular}

It has been noticeable in Table 8 that activities involving physical responses were only occasionally adopted in Chinese classrooms.

Table 9

Learners’ Attitudes Toward Physical Response Activities

\begin{tabular}{llllllll}
\hline & Willing & Confident & Unwilling & Embarrassed & Anxious & Angry & Other \\
\hline Total & 35 & 2 & 8 & 7 & 8 & 1 & 10 \\
$\%$ & $48.6 \%$ & $2.8 \%$ & $11.1 \%$ & $9.7 \%$ & $11.1 \%$ & $1.4 \%$ & $13.9 \%$ \\
\hline
\end{tabular}


According to Table 9, about half of the participants were pleased to attend physical response activities. They viewed this kind of activity as a chance of relief, making class atmosphere easy and relaxed. They also argued that physical movements sometimes enhanced cognitive processing and promoted the turning from input to intake.

These activities make me feel relaxed. [France]

Sometimes the body movements help the brain work. I can remember more. [Germany]

Table 10

The Frequency of Task Adjustments Based on Learners' Need

\begin{tabular}{lllllll}
\hline & Never & Seldom & Occasionally & Sometimes & Mostly & Always \\
\hline Total & 0 & 9 & 10 & 14 & 24 & 13 \\
$\%$ & $0 \%$ & $12.5 \%$ & $13.9 \%$ & $19.4 \%$ & $33.3 \%$ & $18.1 \%$ \\
\hline
\end{tabular}

Based on Table 10, Chinese instructors often adapted the tasks according to their students’ need.

Table 11

Learners’ Attitudes Toward Task Adjustments Based on Learners’ Need

\begin{tabular}{lllllll}
\hline & Satisfied & Comfortable & Dismayed & Anxious & Angry & Other \\
\hline Total & 56 & 6 & 1 & 3 & 2 & 2 \\
$\%$ & $77.8 \%$ & $8.3 \%$ & $1.4 \%$ & $4.2 \%$ & $2.8 \%$ & $2.8 \%$ \\
\hline
\end{tabular}

It was found in Table 11 that the majority of participants felt comfortable with the task adjustments, implying that the most adjustments were appropriate. A large number of learners pointed out that the adjustment often made the task more comprehensible and therefore reduced their anxiety. A few participants who were not satisfied with the adjustments complained that sometimes the instructor incorrectly changed the task to be more difficult or more boring.

The teacher would make the task easier, which is good for me to complete. [Japan]

I would be less nervous if the teacher asked me to finish an easier task. [Spain]

Sometimes I felt really bad when teacher added more complex words to the task. [Germany]

Table 12

The Frequency of Opportunities to Give Presentations

\begin{tabular}{lllllll}
\hline & Never & Seldom & Occasionally & Sometimes & Mostly & Always \\
\hline Total & 1 & 11 & 17 & 26 & 13 & 3 \\
$\%$ & $1.4 \%$ & $15.3 \%$ & $23.6 \%$ & $36.1 \%$ & $18.1 \%$ & $4.2 \%$ \\
\hline
\end{tabular}

Table 12 demonstrated that it was not common for learners to give presentations in Chinese classrooms.

Table 13

Learners' Attitudes Toward Opportunities to Give Presentations

\begin{tabular}{lllllc}
\hline & Willing & Confident & Unwilling & Anxious & Other \\
\hline Total & 14 & 9 & 3 & 37 & 9 \\
$\%$ & $19.4 \%$ & $12.5 \%$ & $4.2 \%$ & $51.4 \%$ & $12.5 \%$ \\
\hline
\end{tabular}


It was listed in Table 13 that about half of the participants felt nervous when giving presentations. Their main reason was that they were worried about the potential mistakes they might have in their presentations. While there were some participants willing to do the public speaking, who viewed it as a good chance to practice their $\mathrm{L} 2$.

I don't like to give an open talk to my classmates. I fear that I may make some mistakes and lose my face. [South Korea]

I can practice my Chinese when I speak publically. [France]

Table 14

The Frequency of Drills

\begin{tabular}{lllllll}
\hline & Never & Seldom & Occasionally & Sometimes & Mostly & Always \\
\hline Total & 0 & 2 & 9 & 18 & 30 & 13 \\
$\%$ & $0 \%$ & $2.8 \%$ & $12.5 \%$ & $25 \%$ & $41.7 \%$ & $18.1 \%$ \\
\hline
\end{tabular}

It could be seen in Table 14 that drill was a commonly used instructional activity in Chinese classrooms.

Table 15

Learners' Attitudes Toward Drills

\begin{tabular}{lllll}
\hline & Satisfied & Dismayed & Anxious & Other \\
\hline Total & 50 & 7 & 7 & 7 \\
$\%$ & $69.4 \%$ & $9.7 \%$ & $9.7 \%$ & $9.7 \%$ \\
\hline
\end{tabular}

From Table 15, a majority of participants expressed their positive feelings toward drills. They believed that drills provided them with opportunities to both practice L2 and receive corrective feedback from the instructor. Some participants also admitted that drills were often boring because of their repetitive and focus-on-form nature. The Cod-liver Oil Syndrome reported by Nicolson and Adams (2010) was also detected in this study. Some learners stated that although they did not like drills they still recognized its facilitative effect on their $\mathrm{L} 2$ acquisition.

Drills are good chances of practice. [Japan]

Drills are too boring, not interesting at all. I feel tried. [Australia]

I know I have to practice in drills although they are often boring. [Germany]

Table 16

The Frequency of In-Class Quiz

\begin{tabular}{lllllll}
\hline & Never & Seldom & Occasionally & Sometimes & Mostly & Always \\
\hline Total & 1 & 15 & 13 & 27 & 12 & 4 \\
$\%$ & $1.4 \%$ & $20.8 \%$ & $18.1 \%$ & $37.5 \%$ & $16.7 \%$ & $5.6 \%$ \\
\hline
\end{tabular}

It showed in Table 16 that in-class quiz was sometimes employed as a part of instruction.

Table 17

Learners’ Attitudes Toward In-Class Quiz

\begin{tabular}{lllllll}
\hline & Willing & Confident & Unwilling & Dismayed & Anxious & Other \\
\hline Total & 27 & 6 & 4 & 1 & 27 & 7 \\
$\%$ & $37.5 \%$ & $8.3 \%$ & $5.6 \%$ & $1.4 \%$ & $37.5 \%$ & $9.7 \%$ \\
\hline
\end{tabular}


It has been evident in Table 17 that participants were divided almost equally into two groups, one with positive feelings and the other with negative attitudes. Those more optimistic learners argued that in-class quiz would evaluate their learning outcomes and sometimes served as an encouragement for their further progress. The anxiety group attributed their nervous feelings to their inadequate preparation and their tendency to be anxious in face of any exam.

I can know what I've learned through the quiz. [Indonesia]

I will work harder if I did not well in quiz. [Japan]

I never prepared well for the exam. I never liked the exam. [France]

I'm always nervous before an exam, any exam. [United States]

Table 18

The Frequency of Multimedia Technology Application

\begin{tabular}{llllllc}
\hline & Never & Seldom & Occasionally & Sometimes & Mostly & Always \\
\hline Total & 13 & 13 & 9 & 17 & 11 & 9 \\
$\%$ & $18.1 \%$ & $18.1 \%$ & $12.5 \%$ & $15.3 \%$ & $15.3 \%$ & $12.5 \%$ \\
\hline
\end{tabular}

Table 18 showed that the classrooms could be classified into two types: one with little technology application and the other with adequate use of technology.

Table 19

Learners’ Attitudes Toward Multimedia Technology Application

\begin{tabular}{llcc}
\hline & Comfortable & Dismayed & Other \\
\hline Total & 51 & 8 & 8 \\
$\%$ & $70.8 \%$ & $11.1 \%$ & $11.1 \%$ \\
\hline
\end{tabular}

It has been displayed in Table 19 that most participants welcomed the introduction of multimedia technology into their classrooms. They thought that multimedia helped draw and concentrate their attention to the learning materials due to its combination of multiple processing channels (e.g., visual, aural, etc.). The drawbacks of multimedia, such as the potential heavy cognitive burden, were also mentioned by learners.

The PowerPoint slides are very interesting. [Germany]

I can more focus on the things taught. [Japan]

Too many pictures make me tired. [Indonesia]

\section{The Most Satisfying and Anxiety-Rousing Instructional Strategies}

The five strategies that participants were most satisfied with were: task adjustments based on learners' need, pair and group work, target language as classroom language, multimedia technology application, and drills (see Figure 1).

There were three strategies that participants were most likely to feel nervous about. They were: opportunities to give presentations, personal information and sensitive topics, and in-class quiz (see Figure 2). 


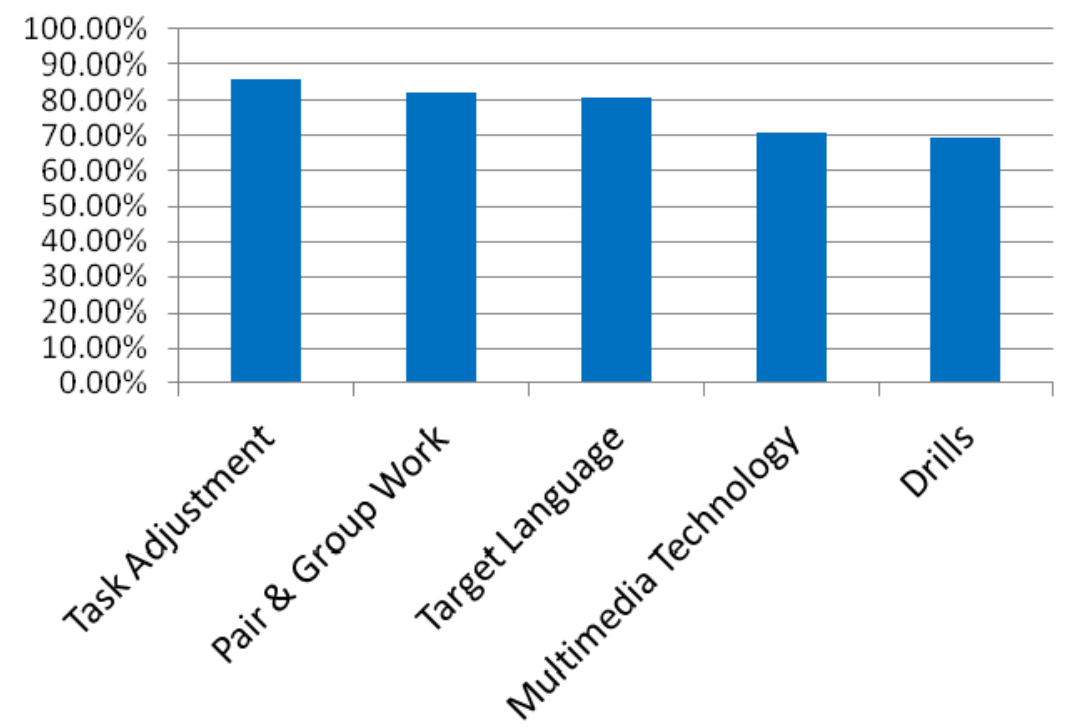

Figure 1. The most satisfying instructional strategies.

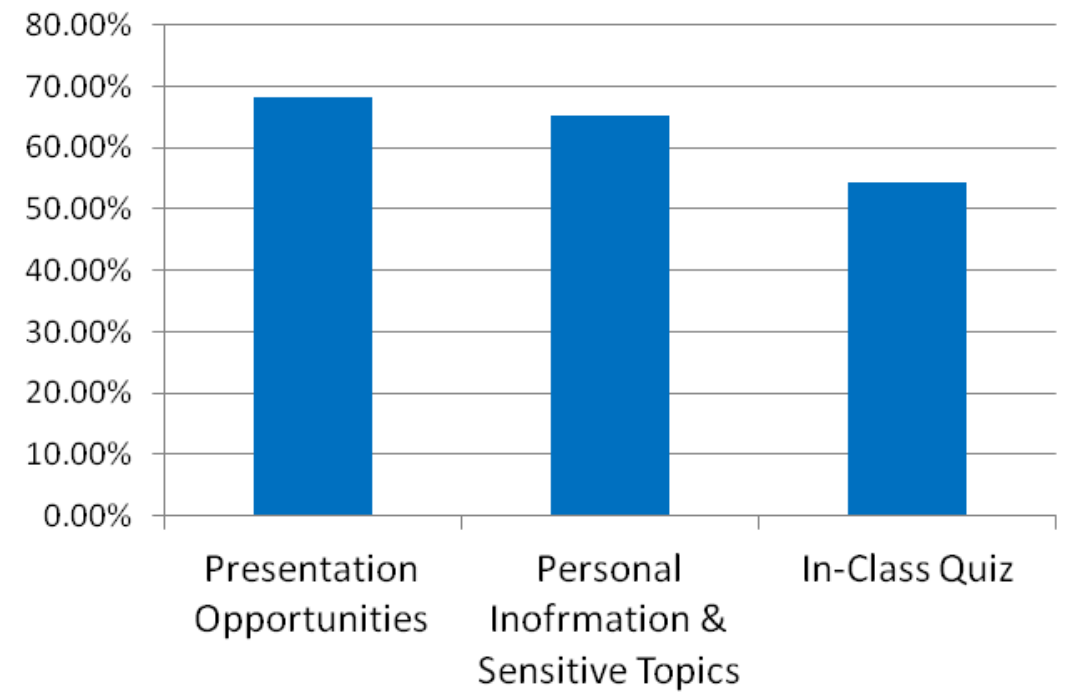

Figure 2. The most anxiety-rousing instructional strategies.

\section{Discussion}

According to the present study, personal information was only moderately used and there was a mixed reaction toward it. The elicitation of personal information in classroom activities has its toot in the theory of episodic memory. First coined by Tulving (2002), episodic memory is the memory of autobiographical events that can be explicitly stated, as opposed to semantic memory of meanings, understandings, and other concept-based knowledge. Second language acquisition involves both kinds of memory. For example, the memorization of L2 vocabulary and grammatical rules requires semantic memory while the incorporation of personal information and experience into language activities calls for the functioning of episodic memory. The present study showed that learners might have different attitudes toward the involvement of personal information, possibly affected by their cultural backgrounds. 
Results of this study also revealed that most participants were comfortable with the wide use of target language in Chinese classrooms. According to Comprehensible Input Hypothesis (Krashen, 1985), language acquisition occurs when there is sufficient comprehensible input. The extensive use of target language provides learners with a large amount of comprehensible input, which facilitates L2 acquisition.

Based on the findings of this study, pair and group work was a common instructional strategy and accepted by the majority of learners. Pair and group work combines input, interaction, and output together during which learners are given opportunities to not only comprehend others and produce their own, but also negotiate meaning and receive feedback (Long, 1996). The positive attitudes held by learners further guarantee the effectiveness of pair and group work in L2 acquisition.

The application of physical response activities origins from Total Physical Response (Asher, 1966), a language teaching method based on the coordination of language and physical movement. In Total Physical Response, instructors give commands to students in the target language, and students respond with whole-body actions. The appropriate use of physical response activities would engage the right hemisphere of the brain and reduce stress in language learning.

Results of this study also demonstrated that instructors often adjusted the task based on learners' needs and most learners have positive attitudes toward such adjustment. Task adjustment is an effort to create an optimal Zone of Proximal Development (Vygotsky, 1978) for learners. The Zone of Proximal Development is the difference between what a learner can do without help and what he or she can do with help. Vygotsky (1978) claimed that the teaching beyond Zone of Proximal Development did not work while the instruction lower than Zone of Proximal Development was always boring. Only the teaching fit the Zone of Proximal Development was effective. When the task is proved to be too difficult for learners to complete independently, the instructor adapts the task, often through reducing the difficulty or providing scaffolding, to fit the Zone of Proximal Development of learners.

There were only a few opportunities to give presentations in Chinese classrooms and different feelings emerged among different learners. Reflecting on her study of immersion teaching (Swain, 1995), Swain developed Output Hypothesis, which states that learning takes place when a learner encounters a gap in his or her linguistic knowledge of the L2. In this study, some learners realized the importance of feedback provided by instructors to narrow the gap between their own production and target language while a number of other learners still fear their mistakes. It is advisable for instructors to encourage those shy learners and build a relaxed classroom atmosphere to reduce the anxiety.

Drill was a commonly used instructional strategy and learner attitudes were quite complex. Frequency Hypothesis (Hatch \& Wagner-Gough, 1976) claims that the acquisition order of different L2 items is determined by the input frequency. The highly frequent items are the first to emerge in learners' production. From this perspective, drill is effective since it allows linguistic items to appear repeatedly. In fact, many learners recognized the importance of the drill in the acquisition and consolidation of L2 items. However, Cognitive Constructivism (Arnold, 2000) argues that language knowledge is actively constructed by learners based on their personal experience instead of being passively received. It is hard to establish new knowledge which is meaningful for learners through the mechanic repetition of drill (S. W. WANG, 2007). Moreover, the repetition which deprives learners of their activeness would cause higher affective barrier and suppress the 
cognitive processing (Arnold, 2000).

In-class quiz was occasionally adopted to measure the learning outcomes. Some participants mentioned that the quiz provided corrective feedback, which drew their attention to the gap between their own production and the target language thus promoted L2 acquisition (Lyster \& Ranta, 1997), while some learners suffered the test anxiety, which refers to the fear, worry, and tension that occur before or during test situation (Zeidner, 1998).

Multimedia technology has been introduced into Chinese classrooms, although not widely applied. Multimedia technology enables learners to process the L2 through multi channels. A lot of participants pointed out that multimedia technology helped them focus more and remember more. According to Mayer (1997), the deep processing takes place when information is dealt with through more than one channel. And the deep processing translates into the stronger mental representation and better acquisition. Meanwhile, the multi channels also lead to heavy cognitive load (Moreno \& Mayer, 2000; DeHaan, Reed, \& Kuwada, 2010) mentioned by some learners, that the simultaneous presentation of sound, script, picture, and animation will be detrimental to the memorization of retrieval of knowledge.

\section{Conclusion}

According to the present study, learners do not accept various instructional strategies uniformly. Learners are satisfied with some instructional strategies such as task adjustment, pair and group work, target language use as classroom language, multimedia technology application, and drills. Other instructional strategies, however, make some learners anxious, such as opportunity to give presentations, the use of personal information and sensitive topics, and in-class quiz.

Pedagogical implications are made based on these findings. Instructors should be aware that learners might hold negative feelings about certain instructional strategies and such negative attitudes would hinder the L2 acquisition. Thus, instructors should be sensitive and flexible when designing tasks and pay attention to learners' emotional response.

\section{References}

Arnold, J. (2000). Affect and language learning. Beijing: LTRP.

Asher, J. J. (1966). The learning strategy of the Total Physical Response: A review. Modern Language Journal, 50, 79-84.

Bailey, P., Onwuegbuzie, A. J., \& Daley, C. E. (2000). Correlates of anxiety at three stages of the foreign language learning process. Journal of Language and Social Psychology, 19, 474-490.

DeHaan, J., Reed, M., \& Kuwada, K. (2010). The effect of interactivity with a music video game on second language vocabulary recall. Language Learning \& Technology, 14, 74-94.

DING, A. Q. (2006a). A study on full-time TCSL teachers' attitudes towards classroom activities. Language Teaching and Linguistic Studies, 1, 57-63.

DING, A. Q. (2006b). An analysis on European-American Chinese learners' perceptions of CSL classroom activities. Chinese Language Learning, 5, 60-66.

DING, A. Q. (2007). Japanese undergraduate students’ perceptions of CSL classroom activities in a Chinese context. Chinese Teaching in the World, 1, 124-135.

Gregerson, T. (2003). To err is human: A reminder to teachers of language-anxious students. Foreign Language Annals, 36, 25-32.

Hatch, E., \& Wagner-Gough, J. (1976). Explaining sequence and variation in second language acquisition. Language Learning, Special Issue 4, 39-47. 
Horwitz, E. K. (2001). Language anxiety and achievement. Annual Review of Applied Linguistics, 21, 112-126.

Horwitz, E. K., Horwitz, M. B., \& Cope, J. A. (1986). Foreign language classroom anxiety. The Modern Language Journal, 70, 125-132.

Krashen, S. (1981). Second language acquisition and second language learning. Oxford: Pergamon.

Krashen, S. (1985). The input hypothesis: Issues and implications. London: Longman.

Liu, M., \& Jackson, J. (2008). An exploration of Chinese EFL learners' unwillingness to communicate and foreign language anxiety. The Modern Language Journal, 92, 71-86.

Long, M. H. (1996). The role of the linguistic environment in second language acquisition. In W. R. Ritchie \& T. J. Bathia (Eds.), Handbook of second language acquisition (pp. 412-68). San Diego: Academic Press.

Lyster, R., \& Ranta, L. (1997). Corrective feedback and learner uptake: Negotiation of form in communicative classrooms. Study of Second Language Acquisition, 20, 37-66.

Mayer, R. E. (1997). Multimedia learning: Are we asking the right questions. Educational Psychologist, 32, 1-19.

Moreno, R., \& Mayer, R. E. (2000). A coherence effect in multimedia learning: The case for minimizing irrelevant sounds in the design of multimedia instructional messages. Journal of Educational Psychology, 92, 117-125.

NI, C. B. (2007). An analysis of the learning needs of international learners of Chinese. Language Teaching and Linguistic Studies, 1, 68-75.

Nicolson, M., \& Adams, H. (2010). The language classroom: Place of comfort or obstacle course?. Language Learning, 38, 37-49.

Scovel, T. (2006). The effect of affect on foreign language learning: A review of the anxiety research. Language Learning, 28, 129-142.

Swain, M. (1995). Three functions of output in second language learning. In G. Cook \& B. Seidlhofer (Eds.), Principles and practices in applied linguistics (pp. 125-144). Oxford: Oxford University Press.

Tulving, E. (2002). Episodic memory: From mind to brain. Annual Review of Psychology, 53, 1-25.

Vygotsky, L. S. (1978). Mind and society: The development of higher psychological processes. Cambridge, MA: Harvard University Press.

WANG, J. Q. (2009). Second language acquisition research. Beijing: The Commercial Press.

WANG, S. W. (2007). Walking into the gate of Chinese teaching. Shanghai: Shanghai Foreign Language Education Press.

WANG, Y. (2004). An investigation of students' and teachers' perceptions of CSL classroom activities. Foreign Language Teaching, 3, 37-44.

WU, S. N., \& LIU, F. F. (2009). An analysis of the learning needs of foreign students with different cognitive styles in CSL classroom. Language Teaching and Linguistic Studies, 4, 77-87.

Zeidner, M. (1998). Test anxiety: The state of the art. New York, NY: Plenum.

ZHANG, L. (2001). Relation between foreign students' learning anxiety and their fluency of spoken Chinese. Applied Linguistics, 3, 44-49. 